\title{
NOTÍCIAS SOBRE AS ESCOLAS DO CAMPO EM GOIÁS:
} um estudo de caso sobre o que a imprensa goiana diz ou oculta sobre o fechamento das escolas

\author{
NEWS ABOUT THE FIELD SCHOOLS IN GOIÁS: a case \\ study on what the press from Goiás says or hides about \\ closing of the schools
}

\begin{abstract}
NOTICIAS SOBRE LAS ESCUELAS DEL CAMPO EN GOIÁS: un estudio de caso sobre lo qué dice u oculta la prensa goiana acerca de cierre de escuelas.
\end{abstract}

\begin{abstract}
Amone Inacia Alves
Resumo: Esse artigo fruto de uma pesquisa de cunho bibliográfico, pretende apresentar como a imprensa goiana tem noticiado sobre o funcionamento das escolas do campo em Goiás, nos anos 2010. Há uma disputa hegemônica sobre como deve funcionar essas escolas, sendo que a imprensa assume um partido e é objetivo desse texto compreender essa origem. Compreendemos que apesar da escola ser um dos instrumentos utilizados pelo campesinato para a transmissão de seus valores e tradições, ela tem sido maculada por um projeto de poder, de dominação econômica e de derrota dessa classe frente aos desmandos do capital. Ela tem sido pensada não a partir das suas especificidades, mas a partir de um projeto de cidade. A imprensa no geral, quando apresenta notícias sobre as escolas, apoia-se nas seguintes categorias de análise: violência, precarização de contratos de professores, transporte escolar. Então é objeto desse texto mapear essas notícias, mostrando o retrato das escolas goianas, a partir da imprensa no Estado.
\end{abstract}

Palavras-chave: Imprensa - Educação do Campo - Projeto político.

\begin{abstract}
This article brings the result of a research of bibliographical nature and seeks to present how the press from Goiás has reported the operation of field schools in Goiás, in 2010. There is a hegemonic dispute on how these schools should work, considering that the press takes a party and the goal of this text is to understand this origin. We understand that despite the school being one of the tools used by the peasantry for the transmission of its values and traditions, it has been tarnished by a project of power, economic domination and
\end{abstract}

\footnotetext{
${ }^{1}$ Doutora em Educação pela Universidade Federal de Goiás (UFG). Atualmente é Professora Associada da Faculdade de Educação da UFG. É Ex-Coordenadora do Curso de Pedagogia da Faculdade de Educação da UFG (2014-2018). Participa como representante institucional do Comitê Estadual do Campo e da Comissão Estadual da Educação do Campo do Estado de Goiás. Atualmente é Vice-Diretora da FE/UFG. ORCID iD: http://orcid.org/0000-0002-3131-6230 . E-mail: amoneinacia@gmail.com
} 
defeat of this class against the misdeeds of the capital. The school has been thought not from their specificities, but from a city project. The press in General, when features news about schools, supports the following categories of analysis: violence, insecurity of contracts for teachers, school bus. Therefore, the objective of this text is to map these news, showing the portrait of the schools in Goiás from the State press.

Keywords: Press - Field Education - Political Project.

Resumen: Este artículo, resultado de una investigación bibliográfica, pretende presentar cómo la prensa de Goiás ha informado sobre el funcionamiento de las escuelas de campo en Goiás en 2010. Hay una disputa hegemónica sobre cómo deben funcionar estas escuelas, y la prensa asume una parte y es el objetivo de este texto entender este origen. Entendemos que, aunque la escuela sean uno de los instrumentos utilizados por el campesinado para la transmisión de sus valores y tradiciones, se ha visto manchada por un proyecto de poder, dominación económica y derrota de esta clase contra el desmantelamiento del capital. Se ha pensado no por sus especificidades, sino por un proyecto de ciudad. La prensa en general, cuando presenta noticias sobre las escuelas, se basa en las siguientes categorías de análisis: Violencia, precarización de contratos de maestros, transporte escolar. Así, el objeto de este texto es mapear estas noticias, mostrando el retrato de las Escuelas Goianas de la prensa en el estado.

Palabras clave: Medios de Comunicación - Educación del Campo - Proyecto Político.

\section{Introdução}

Este texto, fruto de uma pesquisa intitulada Escolas do campo em Goiás: disputas e projetos formativos, pretende mostrar como a imprensa goiana vem, desde os anos 2010, apresentando as escolas do campo nos seus artigos jornalísticos e de opinião. Então, cumpre-nos inquirir nos limites dessa escrita: quais são os destaques sobre a escola contidos nos jornais? Como o noticiário apresenta essas escolas? Como tem sido noticiado o fechamento sistemático dessas escolas?

Noticiários sobre escolas são uma pauta comum na imprensa. Reportagens envolvendo alunos e professores, depredação de patrimônio, violência escolar e outras, povoam as páginas dos jornais escritos, reverberando uma ideia que se tem dessas instituições. Em Goiás não tem sido diferente. Percebemos um uso recorrente de notícias envolvendo escolas, sobretudo, a partir dos anos 2000. A imprensa muitas vezes tem sido espaço para a confluência de um pensamento conservador ${ }^{2}$, a fim de construir uma subjetividade no leitor, que está afinado a ideias do grupo que cria essas ideologias ${ }^{3}$.

\footnotetext{
${ }^{2} \mathrm{~A}$ imprensa tem atuado no apoio a propostas de governos, que ao invés de fazer avançar os direitos, conclama o seu retrocesso, como em ocasião da reforma trabalhista e previdenciária em 2018, quando se viu editoriais de jornais apoiando a edição das reformas. Foi sintomático ainda o papel da imprensa nacional no Golpe impetrado contra a presidenta eleita Dilma Roussef. Por outro lado, a imprensa também atua fortemente na apresentação de casos envolvendo abusos de autoridades, corrupção e ausência de políticas públicas voltadas à população.

3 Tomamos esse termo da acepção materialista dialética, que concebe as ideias elaboradas na sociedade burguesa com a finalidade de escamotear a realidade por meio dos interesses da classe dominante, atrelados ao interesse coletivo para a construção de uma hegemonia. (MANACORDA, 1990)
} 
Essa pesquisa utiliza como fonte documental os jornais impressos, cuja tiragem atinge grande parte do público goiano. Para isso, escolhemos duas fontes jornalísticas: o Jornal O Popular e o Jornal Opção, arquivados na forma on-line.

Para Fonseca $(2003$, p. 12) a imprensa nacional, por meio de seus editoriais e de uma indução do pensamento, contribuiu para a inserção do neoliberalismo na economia brasileira, provocando um "jogo de acomodações e reposicionamentos da grande imprensa em relação a determinados polos de poder, sobretudo o Capital global que representa". Nesse sentido, além de optar por uma linha de pensamento e induzir a compreensão de seus leitores, nota-se um afinamento de ideias com o grande capital, representado pelos empresários, que passam a orientar as edições, conduzindo a mensagem de forma que os leitores incorporem o pensamento, como se fossem por eles produzidos. Acabam adotando um comportamento conservador, reproduzindo-o no cotidiano.

Movimentos conservadores são aqueles que se pautam na censura, no cerceamento ou controle das políticas públicas e na criminalização dos movimentos sociais, objetivando difundir o controle do privado sobre o público, ao mesmo tempo em que engendram um discurso centrado na tradição, na família e na defesa da propriedade. (SILVA e SOUZA, 2008, p.08)

Para tratar dessas questões, faremos uma análise das reportagens produzidas por esses dois jornais goianos. Escolhemos essas duas fontes jornalísticas, pois representam uma leitura pulverizada que forma a opinião dos goianos. Segundo Kreniski (2011 p.01),

[...] o estudo da imprensa vem se constituindo num dos elementos fundamentais para a reconstrução da história, que através do seu intermédio pode aproximar-se das práticas políticas, econômicas, sociais e ideológicas de diversos setores que compõem uma sociedade de forma dinâmica. Dessa maneira a imprensa tornou-se uma fonte rica e diversificada de conhecimentos, não apenas para construção de uma história da imprensa, mas abrindo a historiografia para outras possibilidades de estudo fugindo assim da historiografia tradicional.

Ao eleger o jornal como documento, pretendemos trazer à tona as mudanças e rupturas dos discursos sobre momentos históricos variados na produção do pensamento do Estado. Em geral, não podemos desprezar o fato de que os editoriais dos jornais expressam uma temporalidade sobre o pensamento do que pensam e é divulgado sobre as impressões da sociedade e dos movimentos realizados por alguns grupos.

Não temos dúvida de que compreender a história por meio dos jornais é uma tarefa que envolve um exercício de compreensão. Isso porque a história do jornalismo acompanha a forma como as pessoas produzem o que chamamos de imaginário social sobre práticas, projetos e concepções de mundo. De acordo com o Jornal O Popular, $67 \%$ dos goianos prefere o material impresso às formas digitais (O POPULAR, 2014, p.03). Isso demostra o que falamos anteriormente, sobre a importância dessa fonte para o trabalho de formação do leitor.

Na primeira parte, mostraremos como a imprensa goiana se fez representada por esses dois jornais: O Popular e Opção. A escolha dessas duas fontes se deu por diferentes motivos: a) são dois jornais antigos editados em Goiás, sendo que a escolha se deu em razão de ambos serem jornais que já possuem mais de quatro décadas com 
forte circulação no estado, O Popular criado em 1938 e o Jornal Opção em 1975; b) possuem uma capilaridade no Estado, sendo lidos do interior à capital, estando presentes em diversos municípios; c) são jornais que apresentam diariamente um editorial que expressa a opinião de seus proprietários, o que nos permite analisar os discursos; d) apresentam com certa frequência notícias sobre escolas.

Já na segunda parte mostraremos os avanços e impasses na promulgação da lei do campo. Enfim, no último tópico do texto abordaremos como os dois jornais têm apresentado as escolas do campo e que agendas vislumbram. Pretendemos mapear as manchetes a partir dos anos 2010, marco nas políticas nacionais e no Estado para essa modalidade de ensino.

\title{
A imprensa goiana a partir de dois jornais: O Popular e Opção
}

Descreveremos, de forma breve, o surgimento desses dois jornais e como foram inseridos na história goiana. Falar do jornalismo no Estado é remeter a uma imprensa viva que existe desde 1830, a partir da existência do Matutina Meyapotense. Borges e Lima (2008, p. 203) assim se referem a esse importante jornal goiano:

\begin{abstract}
O período de existência deste jornal engloba os anos de 1830 a 1834. Em linhas gerais, o Matutina foi editado pela primeira vez no dia 5 de março de 1830 , no julgado de Meia Ponte (atual Pirenópolis). Sua história reflete a luta dos jornais brasileiros contra a dominação portuguesa, uma vez que o jornalismo nacional nasceu no ardor e clima dos movimentos políticos, diferentemente da Europa, que teve o desenvolvimento do jornalismo alicerçado principalmente nas necessidades mercadológicas do capitalismo comercial e industrial (BORGES; LIMA, 2008, p. 203).
\end{abstract}

Para as autoras, o século XIX é o período da proliferação de jornais que exprimiam os anseios do grupo criador ou ao objetivo de luta. Elas citam alguns jornais que foram localizados, como: O Enfermeiro dos Doidos, Cartas história da imprensa goiana: ao Povo, Os Dois Compadres Liberais, O Velho Casamenteiro, O Médico dos Malucos, O Minhoca-Verdadeiro Filho da Terra, O Grito da Pátria Contra os Anarquistas, O Carpinteiro José, O Pai José, Teatrinho do Senhor Severo, O Homem de Cor, O Mulato, O Brasileiro Pardo, O Cabrito, O Crioulinho, O Meia-Cara, O Burro Magro, A Loja do Belchior, A Mineira no Rio de Janeiro, O Par de Tetas, A Trombeta dos Farroupilhas, A Sentinela da Liberdade, O Soldado Aflito, O Grito dos Oprimidos, Matutina Meyapontense, dentre outros.

A imprensa goiana, segundo Borges e Lima (2008, p.78), sofreu uma efervescência no campo da produção jornalística, em ocasião da transferência da capital de Vila Boa para Goiânia, cidade recentemente criada. Para se ter uma ideia do número de produções, apesar de que em muitos casos esses escritos tivessem vida curta, em 1939, o estado possuía cerca de 40 periódicos impressos, "sendo 6 jornais e 2 revistas em Goiânia, 5 jornais em Anápolis e 27 jornais em outras cidades do Estado ${ }^{4 " ~(B O R G E S ; ~}$ LIMA, 2008, p.78).

\footnotetext{
${ }^{4}$ Outro periódico de relevância no Estado foi a Revista Oeste. Para Costa (1994) essa revista “operou a serviço da ideologia do Estado Novo, atundo na política de interiorização, seja na mudança da capital para Goiânia ou Marcha para o Oeste.
} 
O jornal O Popular foi criado em 1938, fazendo parte desse processo de publicações da transferência da capital. Pertencente ao grupo Jaime Câmara, responsável tanto pela imprensa falada como escrita em Goiás, ao longo de sua história tem sido o veículo responsável pelas comunicações no Estado.

Segundo o seu primeiro editorial, "pelas folhas volantes deste jornal procuraremos defender a causa das coletividades do Estado, focalizando seus problemas mais vitais e sugerindo para os mesmos medidas solucionadoras". (O POPULAR, 2017). Percebe-se nesse discurso a defesa do jornal em atentar-se às tendências, longe de uma defesa imparcial e neutra, como em ocasião de outros eventos ao longo da história importantes para o Estado, como na época das Diretas Já, em 1984 e no acidente radioativo provocados pelo Césio 137, em 1987.

Já o jornal Opção foi criado em 1975 em Goiânia, obra do jornalista e economista Herbert de Moraes. Para Belém (2015, p. 42),

\begin{abstract}
com o objetivo de criar um jornal de ideias, que se tornasse um veículo iluminista no Estado, Herbert de Moraes viajou com Nanci Guimarães de Melo Ribeiro, sua mulher, para o Rio de Janeiro. Ao voltar, era um homem decidido: faria um jornal moderno e capaz de lutar contra o atraso e a modorra para defender aqueles que tivessem propósitos modernizadores do Estado. Havia quem, adepto do comodismo, sugerisse que fazer jornal de ideias - sempre incontroláveis - em plena ditadura não era "bom" para o jornalismo e para os negócios. Obstinado, Herbert de Moraes acreditava que, com o uso inteligente das frestas, era possível fazer jornalismo crítico e responsável e contribuir para a redemocratização.
\end{abstract}

É importante ressaltar que o jornal Opção surgiu no período da ditadura civilmilitar, sendo um cenário de ideias muitas vezes contraditórias, expondo diferentes pontos de vista sobre um mesmo tema. Em Goiás foi um importante articulador de ideias sobre a redemocratização, mostrando crônicas diárias com políticos da época e fugindo da forte repressão que ocorria naquele momento. O jornal Opção tem sido, ao longo da história, conhecido como um veículo de comunicação com opiniões fortes acerca da política, dos governos e de crônicas sobre a cidade, sendo muito lido entre os universitários e a elite intelectual goiana.

\title{
As escolas do campo e as políticas públicas
}

A inserção das escolas do campo nas políticas públicas é bem recente, conquista dos movimentos sociais que empreenderam um esforço de concretização dessas práticas ao longo de suas lutas. Remetemos ao I Enera, em 1997, ao I e II Conec em 1998 e 2002 um encontro onde se pautaram questões voltadas à efetivação de políticas públicas voltadas à educação do campo. Esse conjunto de ações, culminaram em algumas leis, como a Lei n0 12. 960/14 foi criada com o objetivo de estabelecer diretrizes de bases da educação nacional, criando órgão a fim de impedir o fechamento dessas escolas.

Convém afirmar que as escolas do campo são aquelas que estão vinculadas diretamente a uma perspectiva emancipatória de mundo, em relação intrínseca com a cultura camponesa, com seus valores e necessidades. A luta por sua manutenção 
significa a disputa por políticas públicas que garantam seu funcionamento e permanência.

Como diz Leite (1999, p. 72),

A educação rural no Brasil, por motivos sócio-culturais, sempre foi relegada a planos inferiores, e teve por retaguarda ideológica o elitismo acentuado do processo educacional, aqui instalado pelos jesuítas e a interpretação político-ideológica da oligarquia agrária conhecida popularmente na expressão "gente da roça não carece de estudos. Isso é coisa de gente da cidade".

A partir disso buscamos afirmar que, apesar de supostamente superada, ainda vigora a prática do ruralismo pedagógico nas escolas do campo, estas que são muitas vezes vistas como as sobras da cidade ou o produto de uma visão urbanocêntrica. Aliás, sobre isso ouvimos sempre as queixas dos políticos conhecidos em Goiás, que colocam a formação utilitária para a escola do campo, o "saberzinho" necessário (BRANDÃO, 1999) para formar o bom trabalhador do campo. Entende-se que o bom trabalhador é aquele servil, que obedece sem questionar os desmandos do patrão-coronel.

Outra conquista importante para o movimento foi o Parecer CNE/CEB nº 1/2006, conhecido como o Parecer da Alternância, que reconhece a necessidade de repensar o calendário acadêmico, as metodologias utilizadas e as práticas desenvolvidas pelos docentes nas escolas Brasil a fora. A instituição da política pública Pronacampo em 2006 gerou diversos cursos de licenciatura do campo, as LEDOC, inicialmente na UFG, UFS, UFMG e UNB, espalhando-se nos anos seguintes para em torno de 42 instituições de ensino brasileiro que possuem as Ledoc no rol dos cursos ofertados (MOLINA: 2017, p. 589).

Há uma compreensão de que a escola do campo é apenas uma das ferramentas escolhidas dentre as diversas circunstâncias para a produção de vida dos camponeses. Compreendemos que a escola deve estar assentada em um projeto maior de transformação, alterando a lógica de constituição do plano de estudos, com a desfragmentação do currículo, a construção de um vínculo mais orgânico entre o estudo que se faz dentro da escola e as questões de vida de seus sujeitos concretos, como diria Caldart (2011). Esse, sem dúvidas, é o maior desafio da escola do campo.

Em Goiás, a Lei estadual 18.320/13, após uma década de lutas dos movimentos sociais, promulgada em 30 de dezembro de 2013, apesar de falar da necessidade da escola do campo, não aborda as questões objetivas de concretização dessas escolas. Vivenciamos um momento em que escolas do campo têm sido fechadas, professores demitidos ou transferidos e memórias escolares apagadas. De 2002 a 2018 foram fechadas em torno de 30 mil escolas no Brasil. Em Goiás, cerca de 2.214 unidades educacionais deixaram de existir em 19 anos. Como asseverou Jaqueline Cunha (2011, p 23), estudiosa goiana sobre as escolas do campo, daqui a pouco as escolas do campo serão consideradas peças de museus.

Por ser um Estado marcado pelo agronegócio, em Goiás as lógicas da terra de trabalho e terra de negócio são diversas. Na expansão das fronteiras agrícolas não há melindre nenhum em avançar na produção, mesmo que com isso se sacrifique vidas, como na ação realizada de despejar defensivos agrícolas sobre uma escola de 
assentamento em Rio Verde em maio de 2013, atingindo 37 pessoas, sendo 8 adultos (5 professores) e 29 crianças entre 6 e 14 anos (BRASIL DE FATO, 2018 p. 3).

Assoma-se a isso, a crescente criminalização dos movimentos sociais, e consequentemente, às escolas do campo. Recentemente, ouvimos um constante ataque ao MST, que desde os anos 1980 vêm construindo uma escola do campo afinada à cultura camponesa. A história do MST e dos seus professores tem sido bem documentada em trabalhos de: Caldart, Molina, Leite, dentre outros (2011, p. 28]. Em ocasião da criação dos cursos de Licenciatura do Campo em Goiânia, a fala do então deputado federal, Ronaldo Caiado, ilustra bem o preconceito em relação à educação do campo em julho de 2006 ao jornal $O$ Popular:

\begin{abstract}
O curso vai acirrar ainda mais a crise que existe em relação à questão da terra e demonstra o sentimento do atual governo federal que é comprometido com os crimes do campo. [...] daqui a pouco o PCC e o Comando Vermelho também vão querer que universidade crie cursos específicos para criminosos (O POPULAR, apud ELZA SOBRINHA, 2012, p. 60).
\end{abstract}

Dados do INEP mostraram que em dez anos, mais de 560 escolas do campo brasileiras foram fechadas por escassez de recursos, ausência de uma política federal de manutenção das escolas ou desinteresse dos prefeitos. Só para se ter uma ideia desse 'caos' em solo goiano, se em 2000 havia 1824 escolas, em 2015 esse número caiu para 575. Embora a Lei Federal $n^{\circ} 3.534 / 12$ tenha sido criada para impedir o fechamento de escolas, o fato é que pouco se avançou na preservação desse direito às populações que vivem no campo. Para se ter uma ideia da escassez de escolas do campo em Goiás, na região Sudeste do estado, dos 82 municípios da região, apenas 36 possuem escolas no campo, sendo que 46 municípios estão sem escolas (SOUZA, 2016).

Goiás tem sessenta e oito escolas localizadas no campo, sendo a maioria localizada na região central de Goiás, na região próxima à Brasília, na região do Sul goiano e região leste de Goiás, nas divisas de Minas Gerais e Bahia. Souza (2016), em pesquisa realizada nas mesorregiões goianas, notou que as escolas existentes têm em comum a falta de água potável ou de reservatórios adequados, ausência de banheiros, salas de aulas aprazíveis, falta de energia elétrica e de bibliotecas, além das aludidas péssimas condições de acesso. Segundo a autora, essas condições "acabam alimentando a ideia de que estudar na cidade é uma perspectiva mais interessante" (SOUZA, 2016, p. 63).

Sobre o ensino médio, apenas 41 escolas continuam ofertando essa etapa da formação, sendo que nos últimos anos várias escolas foram fechadas. Em algumas regiões do estado esse quadro se agrava, como por exemplo, na região do entorno de Brasília.

\title{
Notícias sobre escolas do campo em Goiás
}

Escolhemos analisar as notícias dos jornais nos anos 2010, em razão Lei estadual $n^{\circ}$ 18.320, promulgada em 30 de dezembro de 2013, que dispôs sobre a política estadual da educação do campo no Estado. Essa lei representou uma simbólica conquista dos movimentos sociais, ao verem a concretização de um projeto de preservação das 
escolas do campo. Encontramos uma série de reportagens em 2018 e 2019 tratando da temática, objeto desse artigo.

Observamos que a imprensa nacional, em decorrência da expressividade dos movimentos sociais, nos anos 2010 foi profícua quanto à divulgação de manchetes $\mathrm{e}$ artigos sobre as escolas do campo. Pautaram seus noticiários: as dificuldades de transporte, o difícil acesso, a formação de professores e o fechamento. Percebemos que devido ao número de escolas fechadas, esse tema pautou o debate de várias reportagens mostrando os impactos disso na educação dos municípios. Os jornais pesquisados foram escolhidos por apresentarem uma produção jornalística sobre o tema com certa frequência. Notamos que o Movimento dos Sem Terra, MST, é bem citado como representante da luta pela educação e escolas do campo nas produções pesquisadas.

Em Goiás não foi diferente. Encontramos várias menções no jornalismo sobre a insuficiência de escolas, totalizando 17 publicações nos dois jornais pesquisados: 2 , fechamento das escolas; 7 , dificuldades de acesso e transporte; e 08, outras questões voltadas aos problemas provocados pela ausência de escolas e o estudo na cidade ${ }^{5}$.

O Jornal O Popularnoticiou em 2018 uma série de reportagens sobre as escolas do campo. Em uma reportagem de capa intitulada: Municípios goianos fecham $71 \%$ das escolas rurais (RODRIGUES, 2018), mostrou que em épocas passadas, o número de unidades do campo chegou a 1,8 mil escolas, contra 528 das atuais. A reportagem apresenta a dicotomia existente entre o que está na lei sobre a garantia de direitos e a realidade apresentada e cita a fala do prefeito de Hidrolândia, Paulo Sérgio de Rezende, sintomática sobre as justificativas para o fechamento das escolas: "Não compensa manter uma escola na área rural para atender a poucos alunos. Fica muito mais oneroso para a prefeitura garantir um ensino de qualidade numa escola rural do que transportar alunos e oferecer ensino na cidade" (O POPULAR, 2018, p. 8).

Outra reportagem apresenta que as mães assumiram a escola rural, a fim de evitar o sacrifício de deslocamento dos filhos, que ficavam horas viajando no transporte escolar até a cidade. Mostra que essas mulheres se uniram e assumiram as atividades na única escola existente em Hidrolândia.

No dia seguinte, 16 de setembro, reiteram a informação da matéria do dia anterior no editorial:

O desenho da política nacional de educação termina por incentivar os prefeitos a esse caminho. O Fundo de Manutenção do Desenvolvimento da Educação Básica (FUNDEB), por exemplo, é perpassado conforme o número de alunos. Numa escola rural, com menos gastos, os gastos com manutenção também se mantêm praticamente estáveis (RODRIGUES, 2018, p. 36).

Encontramos outras reportagens do jornal $O$ Popularque versaram sobre as escolas do campo com os seguintes títulos: (13/04/2018) Negado pedido de despejo contra escola; (15/09/2019) O futuro do campo; (21/09/2018) Sobre o transporte escolar; (15/09/2018) Prova do Saeb 2017 mostra diferenças de desempenho. Observamos que

${ }^{5}$ No ano de 2017 vários canais de televisão e os jornais noticiaram o caso das estudantes de Cavalcante, comunidade quilombola do interior do Estado que, pela ausência de escolas, eram enviadas para a cidade para estudar. Vivendo como empregadas domésticas, essas crianças foram violentadas por proprietários da região. 
todas essas reportagens entrevistaram pesquisadores das universidades, apresentando dados alarmantes sobre o cenário dessas escolas. Não localizamos reportagens que citassem a lei $n^{\circ} 18.320 / 13$ ou os impactos dessa lei na educação do Estado, no Jornal O Popular.

O Jornal Opção destacou várias temáticas sobre o tema, envolvendo: Críticas ao modelo de militarização nas escolas (2), a destinação dos recursos (1) e reformulação de escolas prejudica pais, alunos e professores de Goiânia (1). Identificamos que esse jornal tem apresentado críticas às propostas de educação adotadas no Estado, expressas no editorial, nos artigos de opinião e nos entrevistados das reportagens.

Um artigo chama a atenção, intitulado: Sem espaço, escola municipal de região rural de Goiânia não consegue atender famílias, publicado em 06 de outubro de 2018. Nele, vimos que é apresentado o quadro de precariedade que assola as escolas do campo, desde a ausência de banheiros para receber mais alunos, como a ausência de vagas para atender às diferentes faixas de idade dos estudantes.

O jornal Opção também fez quatro reportagens sobre o despejo do defensivo Engeo Pleno, usado no combate de pragas nas lavouras de milho e sorgo em uma escola em Rio Verde em maio de 213, município goiano, quando 122 alunos entre 7 e 16 anos foram contaminados pelo produto, apresentando náuseas, coceiras pelo corpo e dor de cabeça.

\section{Considerações finais}

Notamos que a imprensa goiana, estudada aqui em dois jornais, tem noticiado como as escolas do campo estão negligenciadas e esquecidas. Abordam também o quanto há ausência do Estado na manutenção dessas escolas. Os jornais têm mostrado em seus editoriais, como a definição da política educacional está mais delineada a partir de demandas específicas oriundas do agronegócio e das escolas da cidade, do que afinada aos interesses das comunidades rurais. Apresentam um tensionamento entre governo e movimentos sociais, por qual projeto de sociedade se quer vislumbrar na escola no campo.

O que observamos é que, ainda que haja garantia da legislação para os direitos dessa população, o que se observa é exatamente o contrário e isso tem sido mostrado pelos jornais. Além do fechamento das escolas, há o alto índice de analfabetismo entre jovens e adultos, a ausência de água potável e saneamento básico na maioria das escolas e a ausência de tecnologias que promovam e inclusão digital para os jovens que estudam nessas escolas, o que favorece a migração involuntária para as cidades.

As reportagens mostraram o quanto as escolas do campo em Goiás têm sido fechadas, professores demitidos ou transferidos e memórias escolares apagadas. Segundo mostramos, foram fechadas em torno de 30 mil escolas no Brasil. Em Goiás, cerca de 2.214 unidades educacionais deixaram de existir em 19 anos. Sobre o fechamento de uma escola, há um silêncio rompido pelas falas dos pais, da comunidade do campo, dos professores e estudantes. 


\section{Referências}

BORGES, Maria Ribeiro Borges; LIMA, Angelita Pereira de. História da imprensa goiana: dos velhos tempos da Colônia à modernidade mercadológica. Revista UFG, Goiânia, UFG, n. 5, ano X, dez. 2008. Dossiê 200 da imprensa no Brasil. p. 68-87.

BRANDÃO, Carlos Rodrigues. 0 trabalho de saber: cultura camponesa e escola rural. Porto Alegre: Sulina, 1999. 163p.

BRASIL. Conselho Nacional de Educação Câmara de Educação Básica. Resolução CNE/CEB $n^{\circ} 1$, de 3 de abril de 2002. Estabelece as Diretrizes Operacionais para a Educação Básica nas Escolas do Campo. Diário Oficial da União, Seção 1, p. 32. Brasília, 9 abr. 2002.

CALDART, Roseli Salete. Licenciatura em Educação do Campo e o projeto formativo: qual o lugar da docência por área? In: MOLINA, Mônica Castagna; SÁ, Laís Mourão (Orgs.). Licenciaturas em Educação do Campo: Registros e reflexões a partir das experiências piloto. Belo Horizonte: Autêntica, 2011.

COSTA, Maria Beatriz Ribeiro. A Revolução de $\mathbf{3 0}$ e a Revista Oeste na Consolidação de Goiânia: do bandeirantismo utópico à concretização do discurso. Goiânia, 1994. 184 p.. Dissertação (Mestrado em História.) - Programa de Pós-Graduação em História, Universidade Federal de Goiás.

CUNHA, Jacqueline Bezerra. Entre o sonho e a esperança: a Escola Ativa no Brasil. In Recil: Repositório Científico Lusófona. 2015. Acesso em http://recil.ulusofona.pt/handle/10437/6121. Acesso em 12/11/2019.

DAUDE, Rodrigo Bastos. Modo de vida dos camponeses no assentamento rural de Vila Boa no município de Goiás. Goiânia, 2018. 182 p. Tese (Doutorado em Educação) - Programa de Pós-Graduação e Educação, Universidade Federal de Goiás.

DULCE, Emilly. Pulverização de agrotóxicos sobre escola segue impune há 5 anos. Jornal Brasil de Fato. São Paulo. 20 de Junho de 2018. Disponível em: https://www.brasildefato.com.br/2018/06/20/pulverizacao-de-agrotoxicos-sobreescola-segue-impune-ha-5-anos . Acesso em: 02 jan. 2020.

ELZA SOBRINHA, Denilza. Vida, formação e educação: o curso de Pedagogia da Terra da Faculdade de Educação da UFG. Goiânia, 2012. 160 p. Dissertação (Mestrado em Educação) - Programa de Pós-Graduação em Educação, Universidade Federal de Goiás.

ESTADO DE GOIÁS. Lei No 18.320 de 30 de dezembro de 2013. Institui a Política Estadual de Educação do Campo, em consonância com a política de educação do campo desenvolvida pela União e pelo Sistema Educativo de Goiás. Disponível em: http://cpisp.org.br/lei-no-18-320-de-30-de-dezembro-de-2013/. Acesso em 0112/2019.

FONSECA, F. O conservadorismo patronal da grande imprensa brasileira. Opinião pública, Campinas-SP, v. 9, n.2, out. 2003. Disponível em: http://www.scielo.br/scielo.php?script=sci arttext\&pid=S0104-62762003000200004 Acesso em: 31/08/2019. 
JOAZEIRO, Nelson Marsílio. dos Santos. Jovens Kalungas de Cavalcante-GO: processos formativos, construções de identidades e trajeto. Goiânia, 2017. 178 p. Dissertação (Mestrado em Educação.) - Programa de Pós-Graduação em Educação, Pontifícia Universidade Católica de Goiás, Goiânia.

KRENISKI, Gislania Carla; AGUIAR, Maria do Carmo Pinto. O jornal como fonte histórica: A representação e o imaginário sobre o "vagabundo" na imprensa brasileira (18891991). In: Simpósio Nacional de História - ANPUH, XXVI Edição, São Paulo, 2011. Anais [...]. Disponível

em:

http://www.snh2011.anpuh.org/resources/anais/14/1300663138 ARQUIVO artigovaga bundos-1.pdf. Acesso em: 15 ago. 2019.

LEITE, Sérgio Celani. Escola rural: urbanização e políticas educacionais. São Paulo: Cortez, 1999. 113 p.

MANACORDA, Mario Alighiero. O princípio educativo em Gramsci. Porto Alegre: Artes Médicas, 1990. 220 p.

MARIANO Marcelo. Sem espaço, escola municipal de região rural de Goiânia não consegue atender famílias. Jornal Opção, Edição 2256, 06 out. 2018. Disponível em: https://www.jornalopcao.com.br/ultimas-noticias/sem-espaco-escola-municipal-de-

regiao-rural-de-goiania-nao-consegue-atender-familias-141532/ Acesso em: 02/08/2019.

MOLINA, Mônica Castaneda. Contribuições das Licenciaturas em Educação do campo para as políticas de formação de educadores. Revista Educação e Sociedade. Campinas, v. 38, nº. 140, p.587-609, jul.-set., 2017. Disponível em: http://www.scielo.br/pdf/es/v38n140/1678-4626-es-38-140-00587.pdf. Acesso em: 02 jan. 2020.

MOREIRA, Sebastiana Aparecida. História e memória da Escola Vale do Rio Doce 1991-2008. Goiânia, 2018. 189 p. Tese (Doutorado em Educação) - Programa de PósGraduação em Educação, Pontifícia Universidade Católica de Goiás.

POPULAR COMPLETA 79 ANOS (O). Jornal O POPULAR, Goiânia, 03 abr. 2017. Disponível em: https://www.opopular.com.br/noticias/cidades/o-popular-completa-79anos-1.1251472. Acesso em: 10 nov. 2019.

ROCHA, Carlos Bastos. O movimento de reordenamento das Escolas Rurais do Município de Bela Vista de Goiás. Goiânia, 2018. 220 p. Dissertação (Mestrado em Educação) - Programa de Pós-Graduação em Educação, Pontifícia Universidade Católica de Goiás.

RODRIGUES, G. Mães assumem escola rural. Jornal O Popular, Goiânia, 15 set. 2018. Disponível em: https://www.opopular.com.br/noticias/cidades/m\%C3\%A3es-assumemescola-rural-1.1618417. Acesso em: 15 ago. 2019.

RODRIGUES, G. Municípios goianos fecham $71 \%$ das escolas rurais. Jornal 0 Popular, Goiânia, $15 \quad$ set. 2018.2 Disponível em: https://www.opopular.com.br/noticias/cidades/munic\%C3\%ADpios-goianos-fecham71-das-escolas-rurais-1.1618411 Acesso em: 18 ago. 2019. 
RODRIGUES, G. Rotinas de sacrifícios para estudar. Jornal O Popular, Goiânia, 15 set. 2018. Disponível em: https://www.opopular.com.br/noticias/cidades/rotina-desacrif\%C3\%ADcios-para-estudar-1.1618412. Acesso em: 13 ago. 2019.

RUI. Justiça mantém condenação de empresa que pulverizou agrotóxico em Rio Verde. Jornal Opção, Edição 2038, 01 ago. 2014. Disponível em: https://www.jornalopcao.com.br/ultimas-noticias/justica-mantem-condenacaoempresa-que-pulverizou-agrotoxico-em-rio-verde-11521/. Acesso em: 10 nov. 2019.

SILVA, André Luiz Batista da; SOUZA, Maria Antônia. Movimentos conservadores no âmbito da educação no Brasil: disputas que marcaram a conjuntura 2014 a 2018. Crítica Educativa, Sorocaba/SP, v. 4, n. 2, p. 7-23, jul./dez. 2018.

$\begin{array}{ll}\text { Submetido em: } & \text { 15-11-2019 } \\ \text { Aceito em: } & \text { 27-12-2019 }\end{array}$

